\title{
A ABORDAGEM HISTÓRICO-CULTURAL: CONCEPÇÕES E DESAFIOS SEGUNDO AS NARRATIVAS DAS PROFESSORAS DE UMA REDE DE ENSINO
}

\author{
CLARICE SCHOWE JACINTO* \\ PROFA. DRA. ELIZABETE CRISTINA COSTA RENDERS ${ }^{* *}$
}

\begin{abstract}
RESUMO
Apresenta resultados de pesquisa que considerou a implementação da abordagem pedagógica com viés histórico-cultural numa rede de ensino do ABC paulista. Partiu-se da pergunta: como se apresenta a abordagem histórico-cultural nas narrativas de professoras numa rede de ensino que afirma ter o currículo orientado por esta abordagem? O objetivo foi levantar indicadores para a implementação da abordagem histórico-cultural, sendo ela caracterizada a partir das narrativas de quatro professoras desta rede. Metodologicamente, optou-se pela pesquisa narrativa, sendo a entrevista narrativa e a roda de conversa os instrumentos de coleta. As autobiografias narradas das professoras oportunizaram a reflexão sobre a prática pedagógica a partir do referencial composto por categorias como educação transformadora, dialogicidade, pensamento crítico, mediação e amorosidade. Como resultado, chegou-se a um inventário da abordagem histórico-cultural sustentado no tripé design teórico/ design político/ design didático, sendo possível verificar a presença da trama conceitual freireana na prática destas professoras.
\end{abstract}

Palavras-chave: Formação docente. Abordagem Histórico-Cultural. Pesquisa Narrativa.

* Concluinte de Mestrado em Educação da Universidade Municipal de São Caetano do Sul

** Professora do Programa de Pós-Graduação em Educação da Universidade Municipal de São Caetano do Sul e orientadora do trabalho. 


\title{
THE HISTORICAL CULTURAL APPROACH: CONCEPTIONS AND CHALLENGES ACCORDING TO THE NARRATIVES OF TEACHERS IN A TEACHING NETWORK
}

\begin{abstract}
It presents results of research that considered the implementation of the pedagogical approach with historical cultural bias in a teaching network of $\mathrm{ABC}$ paulista. It started from the question: how is the historical cultural approach presented in the narratives of teachers in a teaching network that claims to have the curriculum guided by this approach? The objective was to raise indicators for the implementation of the historical cultural approach, being characterized from the narratives of four teachers in this network. Methodologically, we opted for narrative research, with the narrative interview and the conversation wheel being the collection instruments. The autobiographies narrated by the teachers made it possible to reflect on pedagogical practice based on the framework composed of categories such as transformative education, dialogicity, critical thinking, mediation and loving-kindness. As a result, an inventory of the historical cultural approach was reached, based on the tripod theoretical design / political design / didactic design, making it possible to verify the presence of the Freirean conceptual plot in the practice of these teachers.
\end{abstract}

Keywords: Teacher training. Historical Cultural Approach. Narrative Research.

\section{INTRODUÇÃO}

A abordagem histórico-cultural numa rede pública de ensino é o tema deste artigo. Tal abordagem foi apontada como sendo a praticada nas escolas desta rede, o local de atuação profissional desta pesquisadora por dezoito anos. Todavia, se percebia uma série de contradições entre a intencionalidade 
e a prática docente, principalmente em relação à parceria e à participação da comunidade dentro do ambiente escolar. Neste cenário, coloca-se a necessidade de estudarmos esta abordagem no sentido de nos apropriarmos melhor dos pilares conceituais e constituí-la como práxis.

A hipótese levantada a partir da experiência docente da pesquisadora é de que o ensino tradicional, ainda, se sobrepõe na práxis cotidiana nas escolas. Tornam-se relevantes, portanto, pesquisas que contribuam para aprimorar o processo de implantação da referida proposta curricular nas unidades escolares desta rede de ensino.

Surge, então, a questão para a pesquisa: como se apresenta a abordagem histórico-cultural nas narrativas de professores e professoras de uma rede de ensino que afirma ter o currículo orientado por esta abordagem? O objetivo geral, traçado para tratar a questão abordada, se constitui em levantar indicadores que possam contribuir para a implementação do currículo fundamentado nos pilares da abordagem histórico-cultural numa unidade escolar. Nossos objetivos específicos foram:

- Caracterizar a abordagem histórico-cultural a partir das narrativas de professoras que declaram trabalhar com esta abordagem;

- Discutir, em roda de conversa com professoras de uma rede escolar, os elementos balizadores de seu fazer pedagógico cotidiano na perspectiva de uma proposta curricular histórico-cultural;

- Traçar um panorama dos pilares da abordagem histórico-cultural por meio de um inventário com os conceitos fundantes desta abordagem.

Considerando que um dos objetivos desta investigação foi discutir, juntamente com as professoras, os elementos balizadores da abordagem histórico-cultural, optamos por um método que oportunizou o reconhecimento da subjetividade como valor de conhecimento. Neste sentido, esta foi uma pesquisa narrativa 
que coletou seu material documentário por meio da entrevista narrativa e de roda de conversa com os sujeitos de pesquisa. Foram ouvidas quatro professoras da rede pública de ensino pesquisada que declaram praticar a abordagem histórico-cultural no seu fazer docente e com as quais nos comprometemos a zelar pelo seu anonimato adotando nome fictício para cada uma delas.

Ao final desta investigação, com base nas autobiografias narradas das professoras e na revisão bibliográfica, elaboramos um Inventário da Abordagem Histórico-Cultural, estruturando-o em três eixos: o design teórico, o design político e o design didático. Entendemos que este é um objeto de aprendizagem que poderá colaborar com a difusão e entendimento do que é uma abordagem pedagógica histórico-cultural na formação de professores.

\section{A ABORDAGEM HISTÓRICO-CULTURAL: EDUCAÇÃO COMO ATO DIALÓGICO}

Conhecer as concepções e desafios da abordagem histórico-cultural, na perspectiva do fazer pedagógico cotidiano de professores e professoras, constitui-se no fio condutor deste artigo. Conceitos como: interação, experiência social, ensino-aprendizagem, mediação (instrumentos e signos), inacabamento do ser humano, contradição, humanização e cultura serão, aqui, apresentados como aspectos de importância fundamental, merecendo detalhamento.

Autores que se dedicaram aos estudos desta abordagem, a nomearam como histórico-cultural (LIBÂNEO, 1992,) ou sociocultural (MIZUKAMI,1986). Mas os professores da rede pesquisada a nomearam de sócio-histórico-cultural. O termo histórico-cultural nos remete, primeiramente, à corrente da psicologia soviética de base materialista que partiu da compreensão de que o ser humano é histórico e social (somos ser relacional) e está em permanente transformação, articulando-se com a cultura.

Nesse sentido,

A concepção de uma base material em desenvolvimento ao longo da vida 
do indivíduo e da espécie está diretamente ligada ao segundo pressuposto do trabalho de Vigotski, que toca o outro extremo do funcionamento humano: o homem transforma-se de biológico em sócio-histórico, num processo em que a cultura é parte essencial da constituição da natureza humana. (OLIVEIRA, 1993, p. 24).

Neste artigo, optamos por Vigotski (1994) e Freire (1999) como referência teórica, pois ambos têm como base a concepção do sujeito histórico-cultural. Vigotski viveu no período de 1896 a 1934 (faleceu aos 38 anos) em Orsha, na Bielo-Rússia, e Paulo Freire, brasileiro de Recife, viveu de 1921 a 1997 (faleceu aos 75 anos). Vigotski considerava importante aplicar o materialismo histórico e dialético à psicologia e Paulo Freire, adotando Hegel como referência, apontou a relação opressor-oprimido na sua pedagogia dialético- dialógica. (GADOTTI, 2002).

$\mathrm{Na}$ ótica vigotskiana, são as relações que acontecem em determinada cultura que permitem ao ser humano transformar e ser transformado por meio de trocas recíprocas que acontecem durante toda a sua vida. Essa interação dialética se dá entre ele (o ser humano) e o meio social e cultural no qual se acha inserido, contribuindo para o seu processo de humanização.

Assim, destaca:

[...] em sentido mais amplo significa que todo cultural é social. Justamente a cultura é um produto da vida social e da atividade social do ser humano, por isso a própria abordagem do problema do desenvolvimento cultural da conduta nos leva diretamente ao plano social do desenvolvimento. (VIGOTSKI, 1995, p.151).

$\mathrm{Na}$ interação com o outro é que o ser humano se constitui, confirmando a importância da interação social. É nela (e dela) que emergem os signos que constituem a linguagem e a consciência.

Segundo Vigotski,

O uso de signos conduz os seres humanos a uma estrutura específica de comportamento que se destaca do desenvolvimento biológico e cria 
novas formas de processos psicológicos enraizados na cultura. (VIGOTSKI, 1984, p.27).

O princípio da interação social e da linguagem como herança cultural no desenvolvimento da inteligência aponta, ainda, para outro princípio: o da mediação. A mediação,

em termos genéricos, é o processo de intervenção de um elemento intermediário em uma relação; a relação deixa, então, de ser direta e passa a ser mediada por esse elemento. (OLIVEIRA, 1993, p. 26-27).

Valorizando as relações entre as pessoas, as funções psicológicas superiores têm sua origem primeiro no social, para depois serem apropriadas pelo sujeito. Portanto, para Vigotski,

$[u] m$ processo interpessoal é transformado num processo intrapessoal. Todas as funções no desenvolvimento da criança aparecem duas vezes: primeiro, no nível social, e, depois, no nível individual; primeiro, entre pessoas (interpsicológica), e, depois, no interior da criança (intrapsicológica). Isso se aplica igualmente para atenção voluntária, para a memória lógica e para a formação de conceitos. Todas as funções superiores originam-se das relações reais entre indivíduos humanos. (VIGOTSKI, 1994, p. 75).

Conforme foi explicitado anteriormente, Vigotski e Freire se apoiam na dialética. Nesse método, os fenômenos são sempre estudados como processos em movimento e em mudança. Como pensador humanista dialético, Freire entende que a educação é uma prática antropológica. O ser humano, como um ser com raízes espaço-temporais, situado no mundo e com o mundo, é um ser criador e elaborador do conhecimento e, portanto, sujeito da educação. De acordo com Paulo Freire, o ser humano é inconcluso. Está sempre pronto a aprender, enfrenta situações imprevistas, adapta-se a mudanças.

Desta forma, escreve Freire:

Repito, porém, como inevitável, a franquia de mim mesmo, radical diante dos outros e do mundo. Minha franquia ante os outros e o mundo 
mesmo e a maneira radical como me experimento enquanto ser cultural, histórico, inacabado e consciente do inacabamento. Aqui chegamos ao ponto de que talvez devêssemos ter partido. O do inacabamento do ser humano. $\mathrm{Na}$ verdade, o inacabamento do ser ou sua inconclusão é próprio da experiência vital. Onde há vida, há inacabamento. Mas só entre mulheres e homens o inacabamento se tornou consciente. (FREIRE, 1999, p. 55).

Entendemos que Freire e Vigotski se aproximam quando o primeiro afirma que a educação é um ato dialógico, político e o segundo concebe a linguagem como elemento mediador no processo educacional.

O sujeito que se abre ao mundo e aos outros inaugura com seu gesto a relação dialógica em que se confirma como inquietação e curiosidade, como inconclusão em permanente movimento na História. (FREIRE, 1999, p.154).

Segundo Vigotski (1995), a aprendizagem é uma experiência social mediada pela utilização de instrumentos e signos (a linguagem falada e a escrita); é uma experiência social que é mediada pela interação entre a linguagem e a ação. Para este pensador, o bom ensino é aquele que alavanca o desenvolvimento e, nesta perspectiva, a educação considera o desenvolvimento de forma prospectiva.

De acordo com Freire, a aprendizagem é experiência dialógica. Enquanto ensina, o professor aprende e, por meio do diálogo, ambos (docente e discente) ensinam e aprendem mutuamente, buscam juntos a superação da consciência ingênua (em que o indivíduo é saudosista: permanece preso ao passado que considera melhor que o presente definido como inferior, medíocre, vulgar).

Não há docência sem discência, as duas se explicam e seus sujeitos, apesar das diferenças que os conotam, não se reduzem à condição de objeto, um do outro. Quem ensina aprende ao ensinar e quem aprende ensina ao aprender. (FREIRE,1999, p. 25). 


\section{NOS CAMINHOS DE UMA PESQUISA NARRATIVA: VALOR SOCIAL DA PRÁXIS DOCENTE}

Esta investigação pautou-se num percurso de pesquisa narrativa (CONNELLY; CLANDININ, 1996), pois nela encontramos a valorização da memória como um importante recurso para oportunizar a reflexão sobre a concepção do fazer pedagógico dos/das docentes a partir de sua história de vida. O trabalho com a metodologia narrativa nos remete, por consequência, à pesquisa qualitativa, pois considera a práxis dos professores (as) e seu valor social. Permite conhecer a singularidade do universal que nos rodeia. Neste caso, partimos das narrativas de quatro professoras, docentes de uma rede pública de ensino no grande $\mathrm{ABC}$ paulista, que afirmaram trabalhar com a abordagem histórico-cultural. A constituição do material documentário se deu pelos instrumentos da entrevista narrativa e da roda de conversa.

A autobiografia narrada de cada professora iniciava-se após a exibição de um trecho do documentário "Nunca me sonharam”, que apresenta uma memória da prática pedagógica do professor de Matemática. Tanto na entrevista piloto como nas demais realizadas, a mesma pergunta foi feita pela pesquisadora a cada uma das participantes: Professora, você assistiu ao vídeo do professor Rurdiney, que nos contou uma experiência impactante com um de seus alunos que morava na periferia da cidade: que memória sobre o impacto transformador da educação você teria para compartilhar com outros professores?

O breve tempo do documentário apresentado causou impacto e afetou as participantes que, a partir do depoimento disparador, foram estimuladas a pensar narrativamente sobre suas memórias pedagógicas para posterior transcrição literal.

Considerando que nosso objetivo era levantar indicadores que pudessem contribuir para a implementação do currículo fundamentado nos pilares da abordagem histórico-cultural numa rede de ensino pública, foi importante trabalharmos coletivamente também. Deste modo, propusemos a Roda de Conversa.

Este procedimento se deu após a transcrição das autobiografias narradas. Após a Roda de Conversa devolvemos à rede de ensino pesquisada um Inventário sobre a Abordagem Histórico- 
-Cultural, tendo em perspectiva o apoio na construção da uma abordagem curricular. Este inventário desenvolve-se em três eixos: o design teórico, design político e design didático. Neste artigo, por questão de espaço, somente é possível apresentarmos uma síntese deste inventário, na Tabela 1.

\begin{tabular}{c|c|c}
\hline \multicolumn{3}{c}{ INVENTÁRIO DA ABORDAGEM HISTÓRICO-CULTURAL } \\
\hline Design teórico & Design didático & Design Político \\
\hline Humanização & Dialogicidade & Educação Democrática \\
\hline Dialética & Pensamento crítico & Participação \\
\hline Educação transformadora/libertadora & Prática coletiva/social & $\begin{array}{c}\text { Transformação do sujeito e } \\
\text { do mundo }\end{array}$ \\
\hline Formação social da mente & Prática multi/intercultural & $\begin{array}{c}\text { Acesso ao patrimônio } \\
\text { cultural da humanidade }\end{array}$ \\
\hline Interação Social & $\begin{array}{c}\text { Organização coletiva do } \\
\text { espaço/tempo da aula }\end{array}$ & $\begin{array}{c}\text { Desenvolvimento } \\
\text { e humanização }\end{array}$ \\
\hline Mediação & $\begin{array}{c}\text { Partilha de diferentes } \\
\text { signos e Instrumentos }\end{array}$ & $\begin{array}{c}\text { Solidariedade e justiça } \\
\text { cognitiva }\end{array}$ \\
\hline
\end{tabular}

Autoria: Jacinto, C.S., 2019

Entendemos o inventário como um instrumento de organização e análise dos dados e resultados da pesquisa. Assim, o inventário resulta de:

[...] paciente gesto de recolher peças e remover-lhes o pó depositado com o tempo; raspar de leve, camada por camada, e desvelar o que havia se acomodado embaixo delas; desfazer as nervuras do tempo que, propositalmente ou por ação, se dobraram sobre o que precisava ser dito; organizá-las de modo a construir e reconstruir um sentido do todo a partir de cada fragmento, num jogo de contínuo cotejamento. (LIMA, 2003, p. 31).

Deste modo, realizamos o inventariamento dos resultados desta pesquisa no sentido de contribuir com a rede de ensino pública que pretenda trabalhar fundamentada na abordagem pedagógica histórico-cultural. O inventário produzido foi disponibilizado por meio de um blog. 


\section{AS NARRATIVAS AUTOBIOGRÁFICAS DAS \\ PROFESSORAS: EM PERSPECTIVA OS \\ HORIZONTES EPISTEMOLÓGICOS DA \\ ABORDAGEM HISTÓRICO-CULTURAL}

Ao retomar as autobiografias narradas, delas nos aproximamos à procura de janelas que abram horizontes epistemológicos (COSTA-RENDERS, 2018) rumo à abordagem histórico-cultural em uma rede de ensino que autodeclara nesta abordagem se fundamentar. Partimos do pressuposto que a leitura de mundo e a leitura da palavra são "dialeticamente solidárias". (FREIRE,1998, p.106).

Esses horizontes epistemológicos da abordagem em questão foram aproximados ao elenco de categorias apresentadas no inventário proposto, que ora destacamos: as relações sociais, a perspectiva dialógica, a humanização acrescida da afetividade, a educação transformadora, o pensamento crítico e a prática multi/ intercultural. As narrativas dos sujeitos de pesquisa possibilitaram o decifrar crítico das relações sociais pelo/a docente que, no inventário aqui apresentado, são consideradas no âmbito do pensamento crítico, da dialogicidade e da educação democrática.

\section{A ESCOLA E SEUS MUITOS AFETAMENTOS PELAS HISTÓRIAS DE VIDA}

A professora Gabriela conta que recebeu um educando nascido no Egito que, no entanto, viveu na Síria com sua família trazendo de lá a cultura/ os hábitos daquele país. Mas o acolhimento dessa criança na escola não se deu tranquilamente, nem para a professora, nem para a criança. As dificuldades com o novo idioma, a diferença das culturas, tudo foi levado em conta nas suas ações. Destaca-se principalmente a atenção e o respeito necessários para com a criança e a sua família.

Passados os momentos de adaptação e de um processo complexo de aprendizagem fundamentado nos princípios socioculturais e na prática multicultural, a professora Gabriela relata 
que a educação transformou a realidade da criança. "Nós fomos até a casa dela e eles ficaram muito felizes de nos ver lá, nos receberam como visita na sua própria casa", explica a professora Gabriela (2019). Creio que a criança "percebe que ela pode estar integrada, ela pode estar inserida numa outra sociedade que não aquela que ela vivia, né, nessa nova etapa da vida dela", reforça Gabriela (2019).

Estas narrativas apontaram para a relevância do envolvimento docente com a realidade do aprendiz. Demonstram a compreensão docente no sentido de que "ensinar exige compreender que a educação é uma forma de intervenção no mundo". (FREIRE, 1998, p.110).

Nesta mesma perspectiva, a professora Fabiana, por sua vez, encontrou a maneira de desenvolver o pensamento crítico dos seus educandos com 8 anos de idade. Ela tomou para si a tarefa mais importante da prática educativo-crítica: de que os educandos, nas suas relações aprendessem a assumir-se como seres sociais e históricos. (FREIRE,1998). Para tanto, convidou-os a escrever uma carta ao prefeito contando os problemas locais daquela comunidade. A professora Fabiana esclarece:

Então, quando as crianças começaram a falar, né, uns que o pai bebia. Então, que elas queriam que o preço da bebida fosse mais caro, o preço do cigarro fosse mais caro, que os policiais se preocupassem mais se a droga entrasse na favela ou não, que era para o pai deles não ter acesso a droga que eles não queriam. As crianças sabiam que uma das opções era o tráfico de drogas, mas elas não queriam essa opção. Então, assim, vi naquela pequena carta que as crianças fizeram - crianças de 8 anos, com problemas sociais muito graves que não era pra criança de 8 anos ter. (FABIANA, 2019).

Esta narrativa aponta para as situações limite e os processos de desumanização presentes na vida das crianças, os quais chegam com elas à escola e desafiam o processo de ensino-aprendizagem em curso. Em outra ocasião, a professora Fabiana incentivou, novamente, as crianças a escreverem porque, se qui- 
sessem, poderiam ser escritoras. Fabiana conta que as crianças lhe responderam: “- Não... Imagina, professora!”.

A professora, então, falou sobre diferentes pessoas, figuras vindas de classes populares que hoje são escritores. As crianças, desde então, passaram a escrever, acreditando em si, mudando de opinião.

Noutra situação, para trabalhar com a questão racial, nos termos da superação dos preconceitos sociais, a professora Fabiana, apoiada na perspectiva de transformação, de mudança da realidade, relata e propõe:

[...] a minha vivência maior é com crianças em situação de vulnerabilidade social. Então, as crianças das escolas em que eu trabalho estão nessa situação e a maioria são negras, negras ou afrodescendentes, né. Elas não se enxergam como negras, não são valorizadas, né. Elas não se valorizam por conta de todo um contexto; então, um dos trabalhos é fazê-las enxergar isso, que elas tem valor sim, e que na história elas tiveram muita participação; que elas são bonitas também apesar da mídia dizer outra coisa. Aí a gente fez uma faixa na sala e ele se dividiram. Quem se acha, que se considerava branco, quem eles consideravam o moreno - que eles chamavam- e quem se considerava negro. Sob a minha visão boa parte era negra. Só que na hora que eles se dividiram eles não se consideravam negros, a maioria foi para o branco e a gente foi conversar um pouquinho do porquê disso, né. (FABIANA, 2019).

Nesse recorte da narrativa, aparecem outros aspectos da abordagem histórico-cultural, como a prática social, a perspectiva dialógica e o desenvolvimento do pensamento crítico, todos voltados para a mudança da realidade dessas crianças. Estes relatos apontam também que a perspectiva da denúncia da exclusão e da demanda por inclusão social está subjacente na abordagem histórico-cultural. Nos termos da narrativa autobiográfica desta professora:

Aí surgem muitas questões, mas o quanto as crianças não se veem nos meios televisivos, revistas, propaganda, como alguém que é bonito. Então, eu não vou ser negro. Negro morre, negro sofre, negro não tem trabalho nenhum. Então é melhor eu falar que eu sou branco. Foi uma 
discussão bem bacana com crianças de 8 anos de novo. E eles falam muita coisa e quando você diz para eles que eles são capazes, utilizando uma dinâmica adequada as crianças compreendem que elas podem, sim, também mudar a realidade delas, que não é tão simples, mas que elas podem, sim. (FABIANA, 2019).

$\mathrm{Na}$ subjetividade das narrativas das docentes que acreditam e praticam a abordagem histórico-cultural há sinais de mudanças advindos de uma educação que transforma. Na perspectiva da professora Ana,

[a]li ocorrem enchentes, a comunidade é baixa e entra muita água. E essa visão de imaginar uma menina do segundo ano salvando a mochila da escola e deixando os brinquedos irem embora é bem o que ele falou: a gente muda, a gente se transforma, cada vez que a gente conversa um pouquinho com essas mães e com essas crianças. (ANA, 2019).

Quando uma criança troca seus brinquedos pela mochila levada pela enchente, ela valoriza e acredita na educação. Trata-se da educação que, não somente transforma a vida desta criança, mas também afeta e muda uma professora. Ambas compreenderam a prática social, as características da sociedade que as rodeia, compreenderam as relações sociais que se movem em meio às contradições. (SAVIANI, 2015).

\section{AS PROFESSORAS QUE APRENDEM E SE DESENVOLVEM, HUMANIZANDO-SE}

As narrativas autobiográficas testemunham o desenvolvimento profissional docente. Nas palavras da professora Mariana: "acho que com o João eu aprendi um pouco mais de tolerância né, tolerância e positividade. Mas, eu falei que ele era muito de bem com a vida, muito, muito, muito”. (MARIANA, 2019). Esse aprendizado da tolerância e de enxergar o cotidiano com maior positividade, embora a dinâmica da sala de aula seja árdua em muitos momentos, sinaliza a idoneidade da docente, auxiliando-a a organizar-se, politicamente, renovando as suas forças. Em vista 
disso, a docente entende a sua prática em relação ao educando em uma perspectiva progressista. Isto nos remete às considerações de Paulo Freire sobre amorosidade:

$\mathrm{O}$ meu respeito de professor à pessoa do educando, à sua curiosidade, à sua timidez, que não devo agravar com procedimentos inibidores exige de mim o cultivo da humildade e da tolerância. [...] Como ser educador, sobretudo numa perspectiva progressista, sem aprender, com maior ou menor esforço, a conviver com os diferentes? Como ser educador se não desenvolvo em mim a indispensável amorosidade aos educandos com quem me comprometo e ao próprio processo formador de que sou parte? Não posso desgostar do que faço sob pena de não fazê-lo bem. (FREIRE,1998, p.74-75).

A gestão da sala da aula exige decisões conscientes que levem a resultados voltados à qualidade na educação. No entanto, o trabalho dos docentes é extremamente desafiador, pois, muitas vezes, eles/as se sentem isolados/as, sozinhos/as no processo. Refletindo sobre a realidade da sociedade e o que efetivamente acontece na relação família/escola, Mariana narra:

[...] eu já tive caso de criança que eu parei de mandar a lição de casa porque eu sabia da realidade daquela criança. Então eu optei por fazer por aquela criança dentro da sala, dentro da escola porque eu sabia que ela não ia ter o apoio que ela precisava dentro de casa e aí não adiantava eu ficar forçando e muitas vezes essa criança era punida, porque a escola de alguma forma reclamava, né. (MARIANA, 2019).

No âmbito da prática social (SAVIANI, 2015), ao conhecer a realidade da criança e da sociedade em que está inserida, a/o docente que pratica a abordagem histórico-cultural, fundamentado na ética, imediatamente toma uma posição política, compreendendo que,

[n]ão importa em que sociedade estejamos, em que mundo nos encontremos, não é possível formar engenheiros ou pedreiros, físicos ou enfermeiros, dentistas ou torneiros, educadores ou mecânicos, agricultores ou filósofos, pecuaristas ou biólogos, sem compreensão de nós mesmos enquanto seres históricos, políticos, sociais e culturais; sem uma compreensão de como 
a sociedade funciona. É isto, treinamento supostamente técnico não dá.

(FREIRE,1998, p.134).

O/a docente no exercício da sua profissão, algumas vezes, como afirma a professora Gabriela, duvida da sua capacidade de saber ensinar e esta reflexão o instiga a qualificar a sua prática por meio da pesquisa, encontrando diferentes maneiras de saber se comunicar.

[...] naquele ano eu várias vezes pensei: será que eu fiz o que eu precisava ter feito? Será que eu consegui atingir essa criança para ele ver o quanto é importante estudar, o quanto é importante...? Eu vi avanços pedagógicos, ele se alfabetizou, mas eu só tive a dimensão da diferença que eu fiz quando eu saí de lá. (GABRIELA, 2019).

Nem sempre os frutos do trabalho são colhidos imediatamente. Além da perseverança, entendemos que somente conhecer e dominar o conteúdo não basta. Isto não garante que o processo de ensino-aprendizagem seja bem-sucedido. Além das habilidades específicas de quem ensina, é preciso conhecer e praticar uma educação humanista nos termos da abordagem histórico-cultural.

[...] o professor deve ter não apenas profundidade de compreensão das matérias específicas que ensina, mas também uma educação humanista abrangente[...] Diante da diversidade dos alunos, o professor deve ter uma compreensão flexível e multifacetada, adequada à oferta de explicações diferentes dos mesmos conceitos ou princípios. (SHULMAN, 2014, p. 208).

$\mathrm{Na}$ mesma narrativa, ainda na perspectiva dialógica, aparece o conflito com outras professoras que se queixavam das crianças do abrigo, cujo material e mochilas eram constantemente esquecidos, prejudicando a rotina e o trabalho pedagógico em sala de aula. As professoras se estressavam e as reclamações não cessavam. Eis um relato autobiográfico da professora Gabriela: 
E aí um dia, né, eu e a diretora na época, falamos:

- Nós vamos levar as professoras no abrigo. Elas precisam conhecer. E foi transformador.

Quando as professoras viram que apesar de todo o cuidado que aquelas crianças recebiam, né, o espaço era limpo, o abrigo tinha uma estrutura muito boa. Mas não é uma casa, né. É como se você tivesse uma casa com cinquenta irmãos. Se numa casa com dois irmãos, às vezes, o material já some, né, às vezes a criança perde, imagina uma casa com cinquenta, né, onde a mochila fica ali e tem outras 49 crianças perto para mexer, para pegar ,né. E o fato de você ver, de você pisar lá e olhar com seus próprios olhos faz toda a diferença. (GABRIELA, 4).

Como podemos perceber, segundo Gabriela, a visita ao espaço das crianças promoveu a transformação docente -, ou seja, trabalhando com o pensamento crítico, é possível que o sujeito e o mundo se transformem. No caso, foi preciso levar a equipe de docentes para conhecer a realidade do abrigo para que todos compreendessem a situação das crianças. Nesse sentido,

[a] mudança do mundo implica a dialetização entre a denúncia da situação desumanizante e o anúncio de sua superação, no fundo, o nosso sonho. É a partir deste saber fundamental: mudar é difícil mas é possivel (destaque do autor), que vamos programar nossa ação político-pedagógica [...]. (FREIRE, 1998, p.88).

A professora Ana, ao narrar o trabalho que teve para aproximar-se de um menino dito "muito estressado e com outros problemas de comportamento", comenta:

Daí a gente não trabalha só na escola, né. Daí isso eu levei para casa. Em casa, meu marido falou assim:

- Traz ele um dia, vamos levá-lo ao cinema.

- Eu sei que não pode, sei que é errado, mas eu falei com a mãe e levei o menino ao cinema. A lição que ele deu foi muito maior pra mim que pra ele né. Ele se maravilhou, pegou na minha mão dentro do cinema porque estava com medo do escuro, a gente vê que, às vezes, uma coisa tão pequena, tão pouco, transforma. (ANA, 2019).

Esta narrativa autobiográfica, levou a pesquisadora Ana a indagar: "por que você pensou que foi errado o que fez por essa criança?" Ela respondeu: "Porque, algumas vezes, tem muitos 
alunos que nunca foram ao cinema, que não foram ao zoológico, que não foram à praia.” (ANA, 3).

No entanto, segundo Freire,

"esta abertura ao querer bem não significa, na verdade, que, porque professor, me obrigo a querer bem a todos os alunos de maneira igual. Significa, de fato, que a afetividade não me assusta, que não tenho medo de expressá-la”. (FREIRE, 1998, p.159).

Neste sentido, nos termos do desenvolvimento profissional docente, a professora Ana aponta algumas lacunas:

[...] damos algumas formações sobre as metodologias que a gente usa para alfabetizar, para educar. Mas, a gente não dá a formação do ser humano, do abraçar, do pegar, do dar carinho do dar atenção... (ANA, 2019).

As narrativas das professoras entrevistadas apontam que, para além do conhecimento pedagógico e do domínio de conteúdo, elas desenvolveram a capacidade do aprender com a experiência. A partir desse tripé (conhecimento pedagógico, domínio dos conteúdos e experiência), planejaram o quê, para quê e como deveriam ensinar desenvolvendo, também, a afetividade rumo à transformação do sujeito e do mundo.

\section{CONSIDERAÇÕES FINAIS}

Nossa pergunta investigativa nos levou a entender como se apresenta a abordagem histórico-cultural nas narrativas de professoras de uma rede de ensino que afirma ter o currículo orientado pela abordagem histórico-cultural. As entrevistas narrativas se constituíram em momentos de reflexão sobre a própria prática, contribuindo para a compreensão do movimento histórico do/da docente em sala de aula. Ficou perceptível que vários fatores interferem nesse movimento: a proposta curricular, o sistema de ensino, as diferenças culturais e os desafios da 
desigualdade social que marca a realidade cotidiana das escolas públicas brasileiras.

As autobiografias narradas apontaram, ainda, para os conceitos balizadores da abordagem histórico-cultural, tais como: interação, experiência social, ensino-aprendizagem, mediação (instrumentos e signos), inacabamento do ser humano, contradição, humanização e cultura. Nem sempre essas palavras se fizeram presentes no foco narrativo, porém, o seu sentido estava ali, muito forte, evidenciando os conflitos vividos e a relação que as professoras estabelecem com as suas concepções de educação.

A professora Mariana, ao narrar suas experiências, destaca as relações humanas e o respeito ao outro. Gabriela, por sua vez, atua junto a seus educandos na perspectiva dialógica, tendo em vista a solidariedade e justiça cognitiva. A afetividade marca as ações da professora Ana junto a suas crianças, a amorosidade se faz presente no enfrentamento dos desafios da realidade social.

$\mathrm{Na}$ narrativa autobiográfica da professora Fabiana, destacam-se a preocupação com a prática social, a perspectiva dialógica e o desenvolvimento do pensamento crítico. Importa, ainda, dar relevância à aproximação de cada uma das professoras com as famílias das crianças e com a comunidade: ambas foram valorizadas e incluídas nos seus planejamentos.

Voltando-nos à roda de conversa, ela resultou na elaboração do Inventário da Abordagem Histórico-Cultural, construído coletiva e colaborativamente, que foi disponibilizado para apoio à rede de ensino pesquisada. Durante o processo, percebemos que as professoras que tiveram oportunidade de trabalharem juntas, na mesma escola, se recordavam do que estava sendo dito pela colega, encontrando maior facilidade em caracterizar o que se achava descrito no eixo temático em discussão.

Percebemos, ainda, que seria importante aplicar essa metodologia nas reuniões pedagógicas semanais. Mas, na continuidade do trabalho com o uso do Inventário da Abordagem Histórico-Cultural, certamente novos horizontes se abrirão rumo 
à reflexão e ao pensamento crítico no contínuo fazer pedagógico nesta rede de ensino.

Acreditamos, enfim, que os conceitos que fundamentam a abordagem histórico-cultural podem tornar a escola mais humana e inclusiva.

\section{REFERÊNCIAS}

CONNELLY, Michael; CLANDININ, Jean. Teacher's Professional Knowledge landscapes: teachers stories -stories of teachers - school stories - stories of schools. Educacional Researcher, Washington D.C., v.25 e n.3, p.24-30, 1996.

COSTA-RENDERS, Elizabete Cristina. A escola inclusiva na perspectiva das pessoas com deficiência. Cadernos de Pesquisa, v. 25, p. 47-66, 2018.

FREIRE, Paulo. Pedagogia da esperança: um reencontro com a pedagogia do oprimido - 5. Ed.-São Paulo: Paz e Terra:1998.

FREIRE, Paulo. Pedagogia da autonomia: saberes necessários à prática educativa - 12. Ed.-São Paulo: Paz e Terra:1999.

GADOTTI, Moacir. Aprender, ensinar. Um olhar sobre Paulo Freire. Abceducatio. v.3, n.14, p. 16-22, 2002.

LIBÂNEO, José Carlos. Tendências pedagógicas na prática escolar. In Democratização da escola pública - a pedagogia crítico-social dos conteúdos. São Paulo: Loyola, 1992.

Disponível em:<http://www.ebah.com.br/content/ABAAAehikAH/libaneo $>$. Acesso em 15 abr 2013.

LIMA, Maria Emília Caixeta de Castro. Sentidos do trabalho mediados pela educação continuada em química. 2003. Tese de doutorado. UNICAMP.Campinas. In Inventário - organizando os achados de uma pesquisa - EntreVer, v. 01, n.01, p. 137-154, Florianópolis, 2011.

MIZUKAMI, M.G.N. Ensino: As abordagens do processo. São Paulo, EPU: 1986

MIZUKAMI, Maria da Graça Nicoletti. Aprendizagem da docência: algumas contribuições de Lee Shulman. Educação, v.29, n.2, p.33-49, 2004 Santa Maria. Disponível em http:www.ufsm.br/ce/revista> 
ANA. Relato autobiográfico. Santo André, (São Paulo), 02 de setembro, 2019.

FABIANA. Relato autobiográfico. Santo André, (São Paulo), 02 de setembro, 2019.

GABRIELA. Relato autobiográfico. Santo André (São Paulo), 02 de setembro, 2019.

MARIANA. Relato autobiográfico. Santo André, 12 setembro, 2019.

RHODEN, Cacau. NUNCA me sonharam. Produção Maria Farinha Filmes, 2017. Disponível em: https://vimeo.com/268099814. Acesso em: 07abr. de 2019 .

OLIVEIRA, Marta Kohl. Vygotsky aprendizado e desenvolvimento um processo sócio-histórico. São Paulo: Editora Scipione, 1993.

SAVIANI, Dermeval. O conceito dialético de mediação na pedagogia histórico- crítica em intermediação com a psicologia histórico cultural. Marxismo e Educação em Debate, v. 7, n. 1, p. 26-43. Germinal: Salvador, 2015.

SHULMAN, Lee. Conhecimento e ensino; fundamentos para a nova reforma. Cadernos Cenpec, v.4, n.2, p.196-229, SP, dez. 2014

VIGOTSKI, Lev Seminovich. A formação Social da Mente. São Paulo: Martins Fontes, 1994.

VIGOTSKI, Lev Seminovich. Historia del desarrollo de las funciones psíquicas superiores. Obras Escogidas III (p. 11-340). Madri: Visor/ Ministerio de Educación y Ciencia,1995.

SOBRE AS AUTORAs:

Clarice Schöwe Jacinto

Graduada em Pedagogia pela Fundação Santo André (FSA), Mestre em Educação pelo PPGE. Mestrado Profissional da Universidade Municipal de São Caetano do Sul (USCS). Professora da Rede Municipal de Santo André, atua na equipe técnica de Coordenação de Estudos Pedagógicos e Curriculares da Prefeitura de Santo André.

E-mail: clariceschowe@gmail.com 


\section{Elizabete Cristina Costa Renders}

Pós-Doutora (2015) e Doutora em Educação (2012) na área de Ensino e Práticas Culturais pela UNICAMP, com pesquisas desenvolvidas sobre a educação inclusiva. Professora permanente no Programa de Pós-Graduação em Educação da Universidade Municipal de São Caetano do Sul (2017-atual). É líder do grupo de pesquisa ACESSI (Acessibilidade escolar e inclusão social) e membro do grupo diretor do INCLUDE - rede internacional de colaboração em pesquisa sobre o design universal para aprendizagem. Em suas pesquisas, destacam-se temas como: educação inclusiva, desenho universal para a aprendizagem, epistemologias emergentes, formação de professores, educação especial na perspectiva inclusiva.

Email: elizabetecostarenders@gmail.com 